\title{
O Mapeamento da Geodiversidade e a Identificação de Geossítios para a Criação de Trilhas Geoturísticas no Vale do Riacho São José, em Caetés-PE
}

The Mapping and Identification of the Geodiversity Geossitios to Create Trails Geoturistic in Valley Stream St Joseph, in Caetés-PE

\author{
Wilson dos Santos Bernardo', Carlos Eduardo Santos de Lima², Samuel Othon de Souza Costa ${ }^{3}$, \\ Daniel Dantas Moreira Gomes ${ }^{4}$ \\ 1, 2, ${ }^{3}$ Estudante do Curso de Licenciatura de Geografia, Universidade de Pernambuco, Garanhuns, Brasil. \\ ${ }^{4}$ Doutorando em Geologia, Universidade do Ceará, Fortaleza, Brasil.
}

\section{Resumo}

Este trabalho apresenta um levantamento e um mapeamento do patrimônio geológico presente na área que corresponde à rede de drenagem do Riacho São José, localizado no município de Caetés, agreste de Pernambuco, a partir das observações e dos estudos realizados nas expedições. A metodologia adotada consiste na revisão bibliográfica e nas saídas de campo para coleta de dados, já para a quantificação foi realizada uma análise dos geossítios com um método que se utiliza da tabela de valores de Gray: valor intrínseco, cultural científico didático. Foram utilizados, ainda, GPS's para determinar a localização dos geossítios e para a definição das possíveis trilhas geoturísticas que proporcionassem o estudo, a apreciação e a preservação de sua geodiversidade.

Palavras-chave: Mapeamento, Geodiversidade, Geossítios, Geoturismo.

\begin{abstract}
This paper presents a surve yand mapping of geological heritage in this area that corresponds to the drainage network of the San Jose Creek, located in the municipality of Caetés, wild Pernambuco from observation sands tudie son the expeditions. The methodology consists of a literature review and fieldtrips for data collection and quantification analysis of geossítios with the methodusing the table of values of gray was taken: intrinsic value, cultural didactic científico, and were used GPS's for determine the loalização geossítios, and the definition of possible trails that provide geoturísticas the study, appreciation and preservation of his geodiversity.
\end{abstract}

Keywords: Mapping, Geodiversity, Geossítios, Geotourism. 


\section{INTRODUÇÃO}

O Brasil, por ser um país que possui um vasto território e, também, por conter em seu território uma grande quantidade de paisagens naturais e diversas formas de relevo de grande valor estético e científico, configura-se como um país de grande geodiversidade. Tais atributos deveriam colocar o Brasil em posição de destaque quanto ao estudo das geociências e quanto ao aproveitamento geoturístico das feições e monumentos geológicos encontrados pelo território brasileiro. No entanto, são poucos os trabalhos referentes ao estudo e à divulgação da geodiversidade.

Um dos conceitos de geodiversidade foi definido em 1993. Na conferência de Malvern, no Reino Unido, sobre conservação geológica e paisagística. A geodiversidade, segundo Brilha: Consiste na diversidade de ambientes e elementos geológicos (rochas, minerais, fósseis), geomorfológicos (geoformas-formas da superfície terrestre, produzidas por feições geológicas e geomorfológicas) e pedológicos, incluindo as suas inter-relações que dão origem às paisagens que são o suporte da vida da Terra. (BRILHA, 2005)

Com base nesse conceito definido por Brilha, a Companhia de Pesquisa em Recursos Minerais (CPRM), com o projeto geoparques do Brasil, iniciou os estudos se referindo a geodiversidade no Brasil. A geodiversidade, conforme a (CPRM 2006), configura-se como:

O estudo da natureza abiótica (meio físico) constituída por uma variedade de ambientes, composição, fenômenos e processos geológicos que dão origem às paisagens, rochas, minerais, águas, fósseis, solos, clima e outros depósitos superficiais que propiciam o desenvolvimento da vida na Terra, tendo como valores intrínsecos a cultura, o estético, o econômico, o científico, o educativo e o turístico.

Nos estudos realizados pela CPRM, pode-se constatar o rico potencial de geodiversidade que o Brasil dispõe em seu território. Até mesmo no semiárido nordestino foram catalogados locais com grande potencial para se tornarem geoparques. Porém, desde a criação da Rede Global de Geoparques pelas Nações Unidas para a Educação, Ciência e Cultura (UNESCO), em 2004, até o momento, apenas o geoparque Araripe (inclusive, é o único da América Latina) reconhecido pela referida instituição. Outros locais na área do semiárido também registraram características pertinentes para a implementação e a identificação de potenciais geoparques. Segundo Bezerra (2011, p.16), "Geoparque é um território com limites definidos, que possui sítios de grande valor científico, [...] que tem papel ativo no desenvolvimento econômico de seu território". Nos seus escritos relacionados ao quadrinômio dos 4 G's: geodiversidade, geossítios, geoturismo e geoparques, Brilha define um geoparque como sendo:

Um território, bem delimitado geograficamente, com uma estratégia de desenvolvimento sustentado baseada na conservação do patrimônio geológico, em associação com os restantes elementos do patrimônio natural e cultural, com vista à melhoria das condições de vida das populações que habitam no seu interior. (BRILHA, 2005)

Essas características que são necessárias para a criação de um geoparque podem ser encontradas em muitas outras localidades no semiárido brasileiro, em especial no estado de Pernambuco. Tal estado já possui unidades de preservação nacional e municipal, com destaque para Pedra Furada, no município de Venturosa, PARNA Vale do Catimbau, na extensão dos municípios de Buíque, Ibimirim e Tupanatinga, Pedra Redonda, no município de Pedra, as cachoeiras, no município de Bonito, todas no agreste de Pernambuco. Esses municípios apresentam, na sua geomorfologia, uma grande quantidade de afloramentos rochosos, cachoeiras e testemunhos geológicos, que se configuram como potenciais geossítios. Um Geossítio, segundo Brilha:

É definido como a ocorrência de um ou mais elementos da geodiversidade, (aflorantes pela ação de processos naturais ou devido à intervenção humana), delimitados geograficamente e que apresentam algum valor (científico, pedagógico, cultural, turístico, etc.). (BRILHA, 2005) No município de Caetés, que também está localizado na Mesorregião do Agreste de Pernam- 
buco, há uma área rica em geodiversidade ainda pouco conhecida. Essa área corresponde aos vales da rede de drenagem do riacho São José, que compreende a rede de afluentes da bacia do rio Ipanema. $\mathrm{Na}$ localidade existe uma grande variedade de formações de rochas; marmitamentos, inselbergs, matacões, algumas cachoeiras e corredeiras, formas de relevo exuberantes e, recentemente, vêm sendo encontradas pinturas rupestres em painéis e furnas, descobertas que incrementam a potencialidade da área para a criação de um geoparque ou para a determinação de geossítios destinados a pesquisa e visitação. Conforme Baci:

Para a criação de um geoparque, é necessário que a região selecionada tenha atributos geológicos e paleontológicos excepcionais e que sua implantação contemple o geoturismo e desenvolva a economia local, De forma a modificar a realidade socioeconômica de seus habitantes. Por isto, que um geoparque, que parte de uma área pré-delimitada, deve ter programas de desenvolvimento sustentável e projetos educacionais (BACI, 2009, P. 08).

Dessa forma, torna-se necessária a criação de medidas para o estudo, divulgação e preservação da geodiversidade presente no local, onde o geoturísmo pode atender a essas necessidades. Conforme afirma Ruchkys, geoturismo é:

Um segmento da atividade turística que tem o patrimônio geológico como seu principal atrativo e busca sua proteção por meio da conservação de seus recursos e da sensibilização do turista, utilizando, para isto, a interpretação deste patrimônio tornando-o acessível ao público leigo, além de promover a sua divulgação e o desenvolvimento das ciências da Terra. (2007, p. 23)

O presente trabalho traz um mapeamento e uma catalogação dos potenciais geossítios que podem representar a geodiversidade do vale do Riacho São José, tornando viável a criação de trilhas geoturísticas como forma de geoconservação, sustentabilidade e divulgação do conhecimento a respeito das geociências.

O município de Caetés está localizado na mesorregião Agreste e na Microrregião Garanhuns do Estado de Pernambuco, limitando-se a norte com Venturosa, a sul com Paranatama, a leste com Garanhuns e Capoeiras, e a oeste com Pedra. A área municipal ocupa $322,9 \mathrm{~km}^{2}$ e representa $0.33 \%$ do Estado de Pernambuco, está inserido na Folha SUDENE de Venturosa na escala 1:100.000. A sede do município tem uma altitude aproximada de 849 metros e possui coordenadas geográficas de 08 Graus 46 min. 23 seg de latitude sul e 36 Graus $37 \mathrm{~min}$. 21 seg de longitude oeste, distando 249,2km da capital, cujo acesso é feito pela BR-101; BR-433, e BR-424.

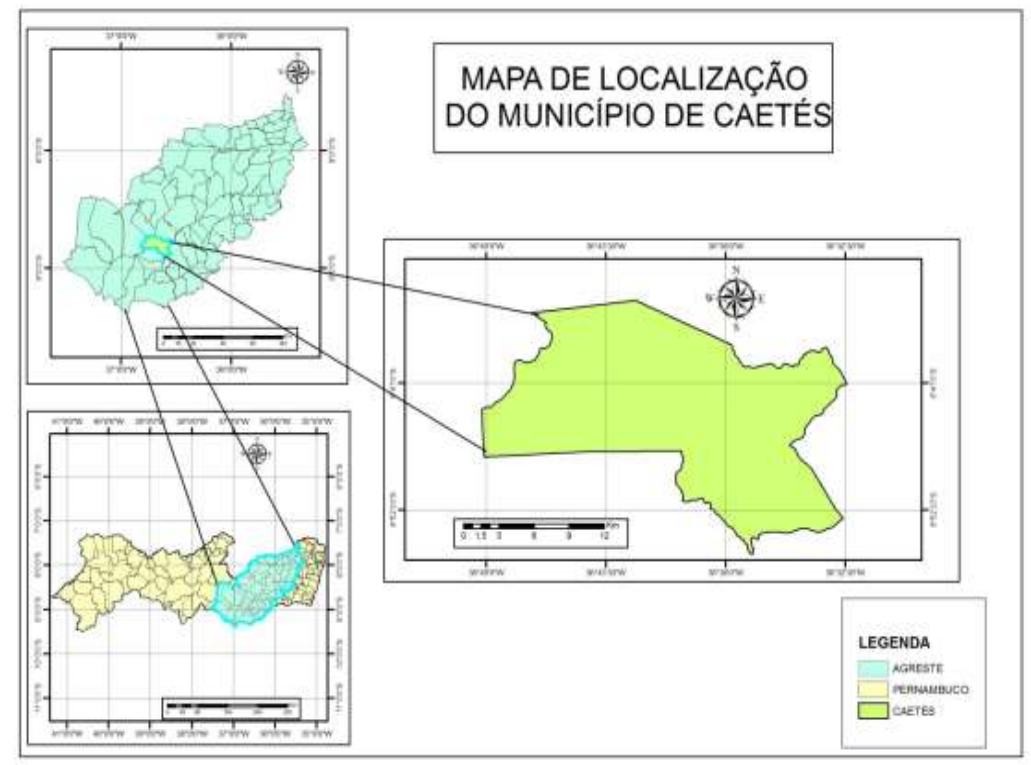

Figura 1: Localização do Município de Caetés.

Fonte: Desenvolvidos pelos Autores. 
Está inserido na unidade geoambiental do Planalto da Borborema, formada por maciços e outeiros altos, com altitude variando entre 650 a 1.000 metros. Ocupa uma área de arco que se estende do sul de Alagoas até o Rio Grande do Norte. O relevo é geralmente movimentado, com vales profundos e estreitos dissecados. Com respeito à fertilidade dos solos, é bastante variada, com certa predominância de média para alta. A área da unidade é recortada por rios perenes, porém de pequena vazão, e o potencial de água subterrânea é baixo. A vegetação desta unidade é formada pela caatinga Subcaducifólia e Caducifólia, próprias das áreas agrestes.

Nas Superfícies suaves onduladas a onduladas, ocorrem os Planossolos, medianamente profundos, fortemente drenados, ácidos a moderadamente ácidos e com fertilidade natural média e, ainda, os Podzólicos, que são profundos, textura argilosa, e fertilidade natural média a alta. Nas elevacões ocorrem os solos Litólicos, rasos, de textura argilosa e com fertilidade natural média. Nos Vales dos rios e riachos, ocorrem os Planossolos, medianamente profundos, imperfeitamente drenados, de textura média/argilosa, moderadamente ácidos, com fertilidade natural alta e problemas de sais. Ocorrem, ainda, Afloramentos de rochas (CPRM).

\section{METODOLOGIA}

A metodologia adotada no presente trabalho consiste na pesquisa de campo, com o levantamento de fotos e visitas aos pontos com adereços que possam classifica-los como potencias goessitios. Com a utilização do GPS, foram demarcados os potenciais geossitios. Com a análise das informações, colhidas nas saídas de campo, foi elaborado um inventário dos O9 (nove) geossitios, avaliados de acordo com os valores de geodiversidade que foram identificados nos pontos analisados.

Durante a fase de revisão bibliográfica, foi realizada uma pesquisa de estudos relacionados aos conceitos de geodiversidade, geoparques e geossítios e, também, a respeito da caracterização do município de Caetés. Durante a fase de campo, foram visitados O9 (nove) locais de grande representatividade geológica e arqueológica, em cada localidade foi feito um registro fotográfico e obtidas as coordenadas geográficas. Para a elaboração da localização da área, foram utilizadas imagens de satélite do google hearth, após determinadas as localizações dos geossitios, foi elaborado um mapa de geossitios de grande valor para o estudo e divulgação da geodiversidade do Vale do riacho São José.

\section{RESULTADOS E DISCUSSÃO}

A escolha dos potenciais geossítios a serem apresentados nesse trabalho levou em consideração os atributos estéticos que possam servir como incentivo para o geoturismo e, também, o seu valor científico e didático que podem ser explorados na área do vale. Com base nesse critério, foram localizados os geossítios: lajeiro liso, bico da seriema, pedra pintada, pedra vermelha, furna do rebeiro e pontos de apreciação da paisagem. Assim como trechos do riacho que possuem características geológicas e estéticas de grande valor e interesse científico. Esses geossítios estão enumerados no mapa, assim como a demarcação de uma possível trilha que possibilite ao visitante a observação da geodiversidade dessa parte do riacho.

A classificação dos geossítios foi definida com base na tabela de valores da geodiversidade proposta por Gray (2004), entre os valores destacados por este autor estão: valor intrínseco, cultural, estético, econômico, funcional e científico/educativo.

O valor intrínseco, conforme destaca Brilha (2005), é o mais subjetivo atribuido a geodiversidade. Para o valor cultural, Brilha (2005) considera, ainda, como valor cultural, o uso de uma dada singularidade geológica como "cartão de visitas" de uma determinada região, o valor econômico não tem, ainda, nenhum aproveitamento na região da pesquisa, pela falta de conhecimento e divulgação a respeito dos atrativos do lugar.

Os valores estético, didático e científico foram os mais representativos nas observações durante a pesquisa de campo, com locais de grande beleza natural e com possibilidade de servir como objeto de pesquisa de campo e ensino sobre as geociências. 


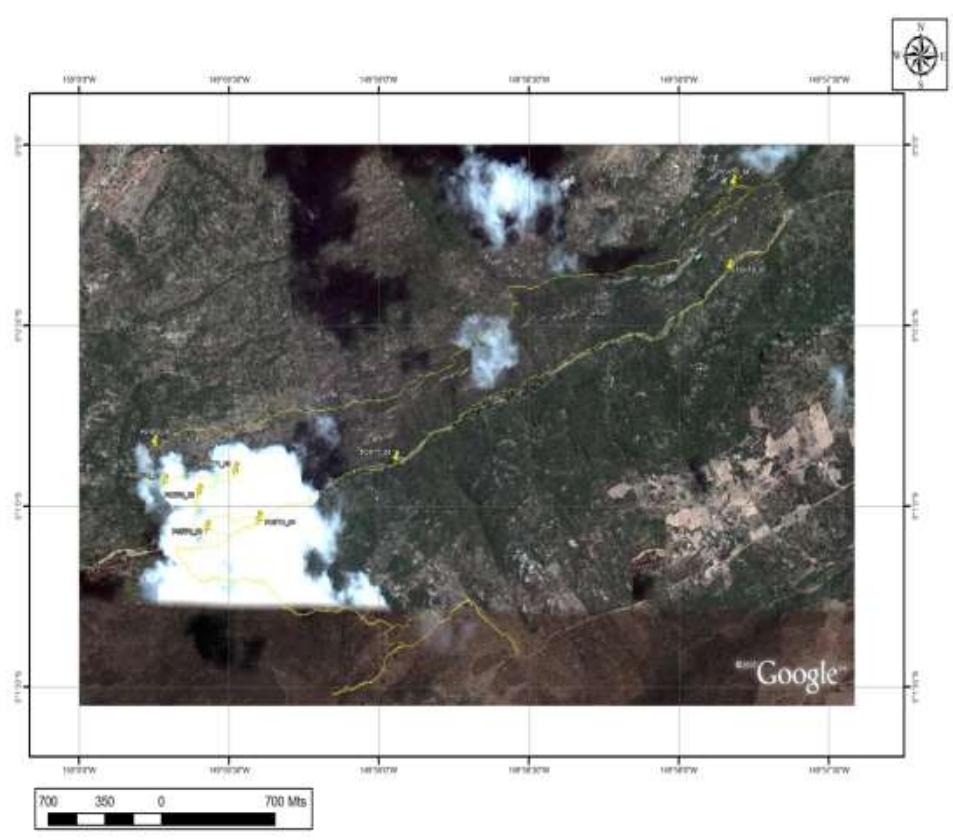

Figura 2: Localização do localização dos potenciais geossítios, onde: ponto 01-Lajeiro Liso; ponto 02-Bico de Seriema; ponto 03- Pedra Pintada; ponto 04-Local de apreciação paisagística; ponto05-Pedra Vermelha; ponto06-Apreciação de formações rochosas singulares; pontos 07/08-Leito do riacho; ponto 09-Pedra do Sol.

Fonte: Desenvolvidos pelos Autores.

Valores da Geodiversidade Presentes no vale do riacho São José, Caetés-PE.

\begin{tabular}{|c|c|c|c|c|c|c|c|}
\hline Tipos & $\begin{array}{l}\text { Potenciais } \\
\text { Geossítios }\end{array}$ & Intrínseco & Cultural & Estético & Econômico* & Funcional & Cientifico\Educativo \\
\hline $\begin{array}{l}\text { Formação } \\
\text { rochosa }\end{array}$ & Lajeiro liso & $\mathrm{A}$ & $\mathrm{M}$ & $\mathrm{A}$ & I & I & $\mathrm{A}$ \\
\hline Furna & $\begin{array}{ll}\text { Bico } & \text { da } \\
\text { seriema }\end{array}$ & A & $\mathrm{M}$ & A & I & I & $\mathrm{A}$ \\
\hline Furna & $\begin{array}{l}\text { Pedra } \\
\text { pintada }\end{array}$ & A & $\mathrm{A}$ & $\mathrm{A}$ & I & I & A \\
\hline $\begin{array}{l}\text { Formação } \\
\text { rochosa }\end{array}$ & $\begin{array}{l}\text { Pedra } \\
\text { vermelha }\end{array}$ & A & A & A & I & I & A \\
\hline $\begin{array}{l}\text { Formação } \\
\text { rochosa }\end{array}$ & Pedra do sol & $\mathrm{A}$ & $\mathrm{A}$ & $\overline{\mathrm{M}}$ & $\mathrm{I}$ & I & A \\
\hline $\begin{array}{l}\text { Rochas } \\
\text { em erosão }\end{array}$ & $\begin{array}{ll}\text { Pontos } & \text { no } \\
\text { leito } & \text { do } \\
\text { Riacho } & \end{array}$ & $\mathrm{A}$ & $\mathrm{M}$ & $\mathrm{A}$ & I & I & $\mathrm{A}$ \\
\hline $\begin{array}{l}\text { Formação } \\
\text { rochosa }\end{array}$ & $\begin{array}{l}\text { Pontos de } \\
\text { observação }\end{array}$ & $\mathrm{A}$ & $\mathrm{M}$ & $\mathrm{A}$ & I & I & $\mathrm{A}$ \\
\hline
\end{tabular}

Figura 3: Tabela de Classificação dos Geossítios. Onde A - Alto; M - Médio; B - Baixo; I - Inexistente. *Valor econômico relativo ao uso turístico atual.

Belezas observadas na geodiversidade do vale do riacho São José 


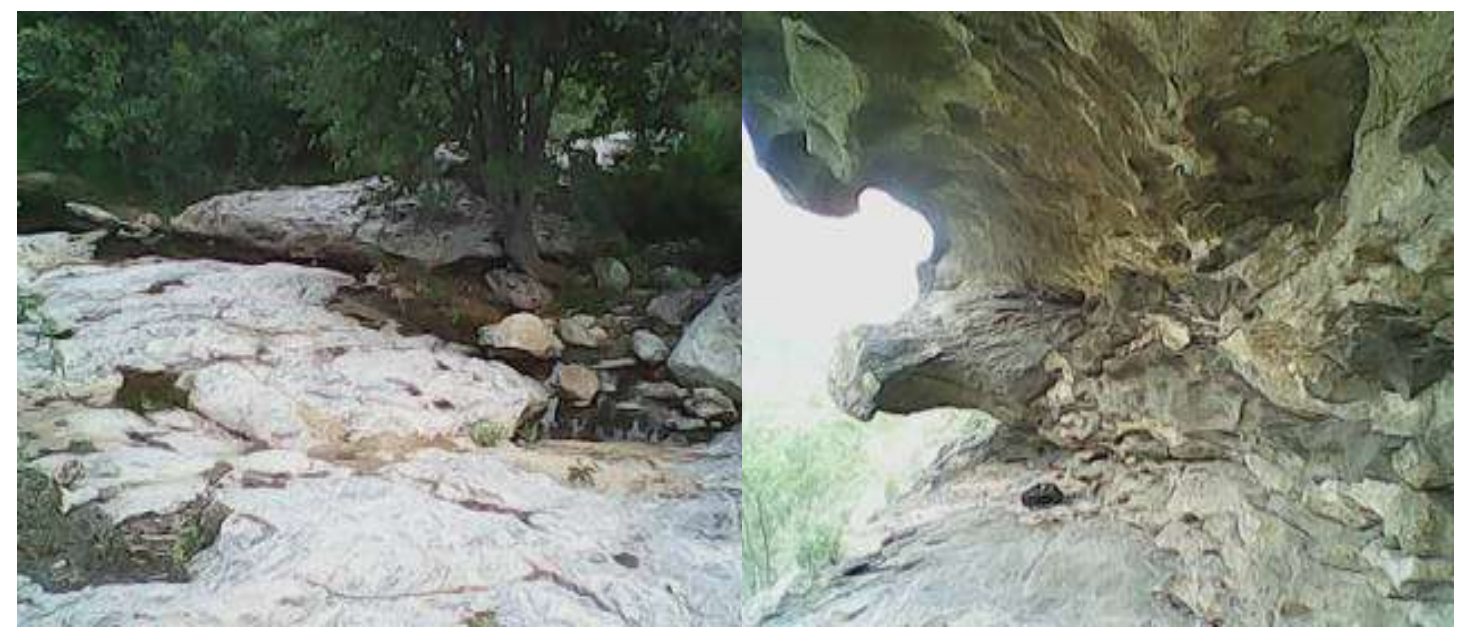

Ponto:01

Ponto:02

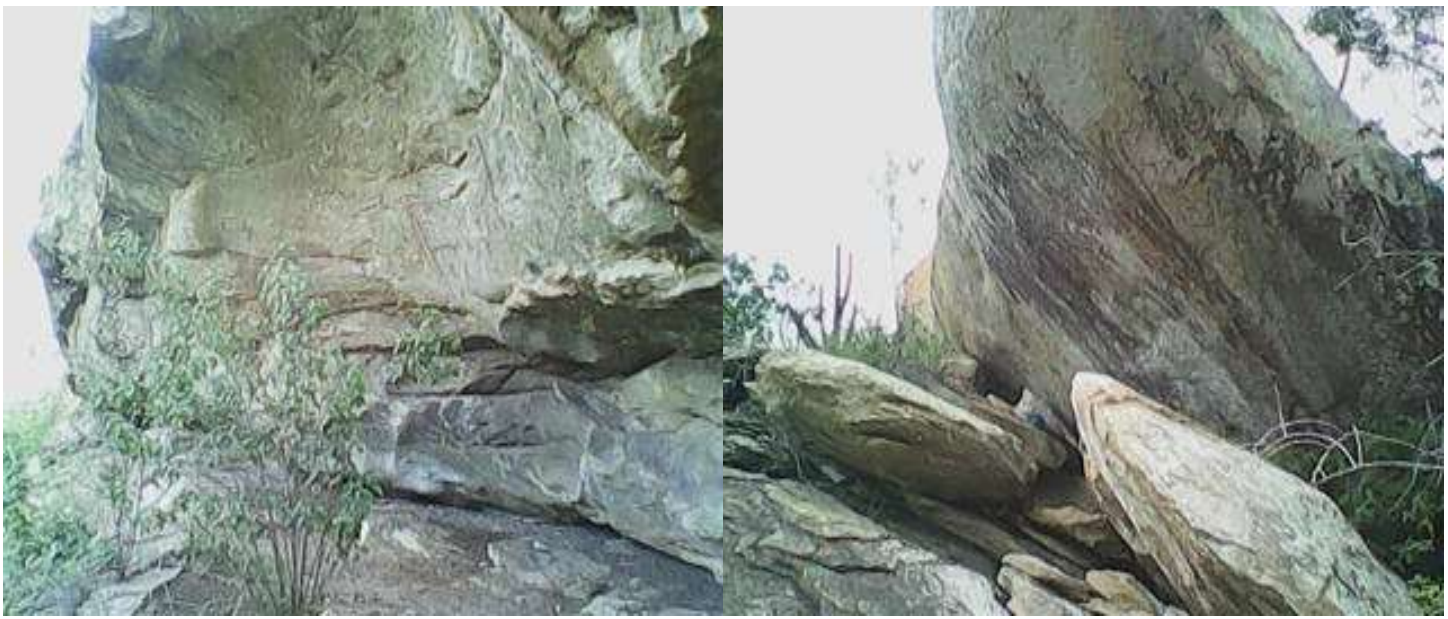

Ponto:03

Ponto:04

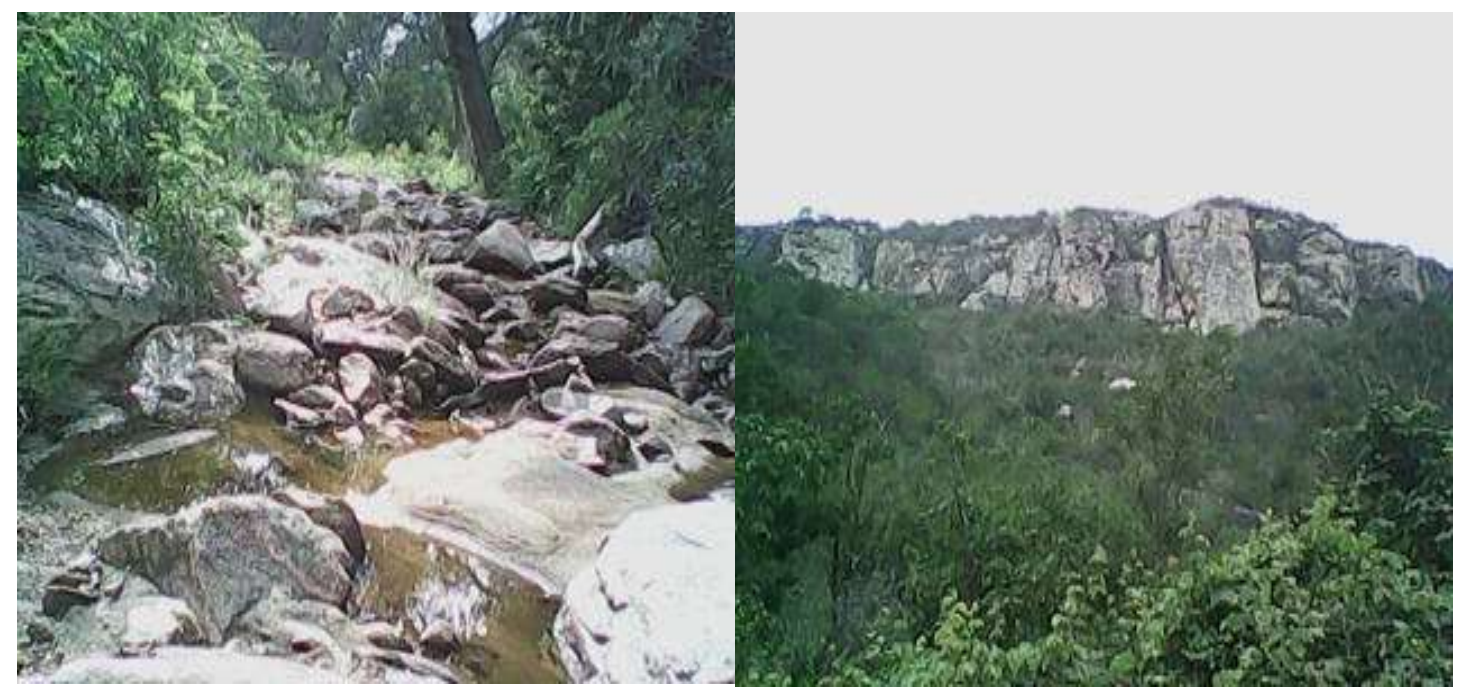

Ponto:05

Ponto:06 


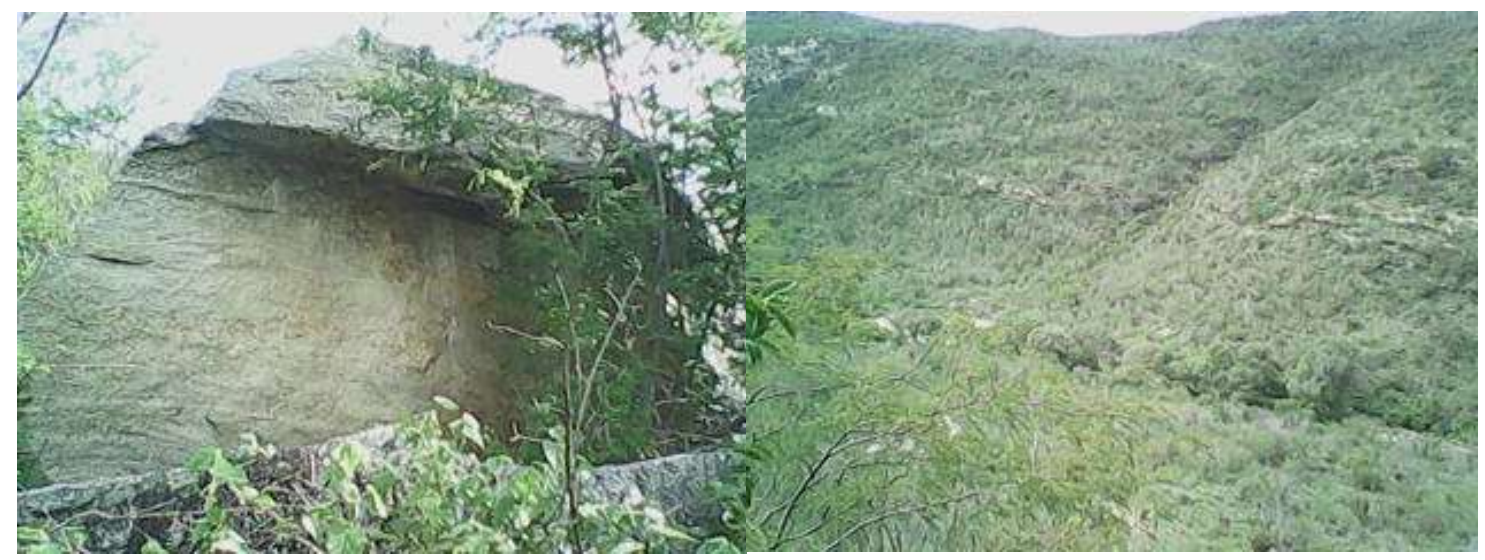

Ponto:07

Ponto:08

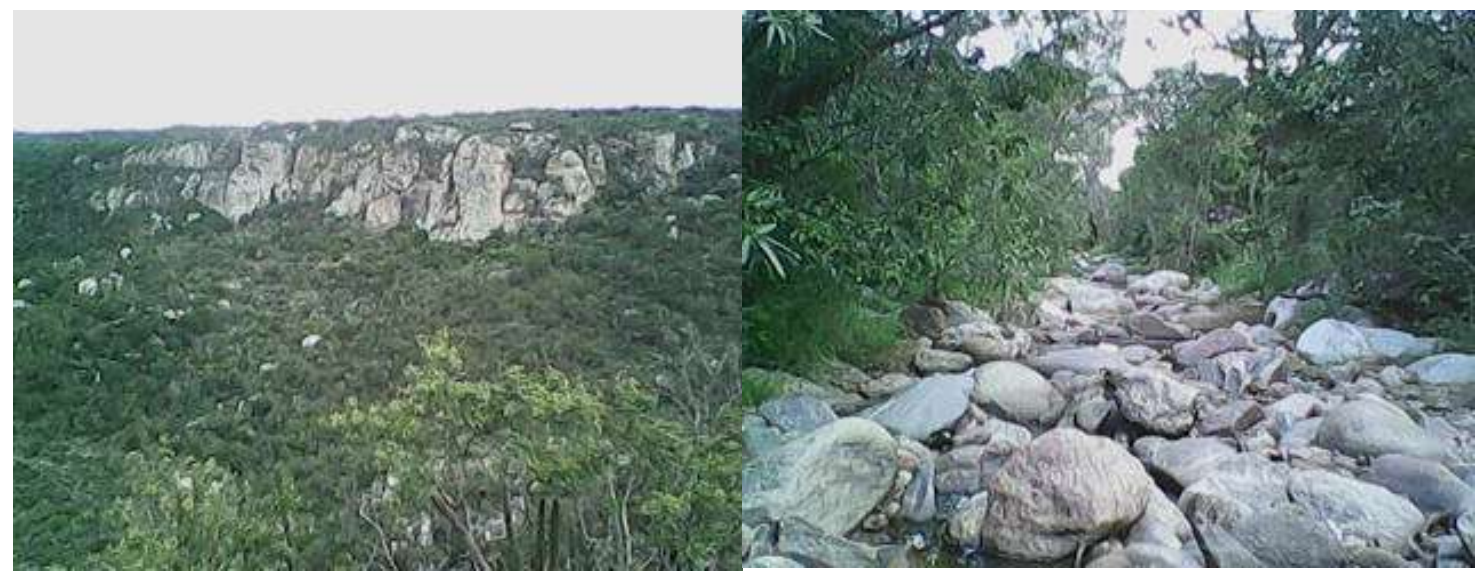

Ponto:09

Ponto: 10

Figura 4: Imagens da Geodiversidade Presente no Vale do Riacho São José. Onde: ponto 01-Lajeiro Liso; ponto 02-Bico de Seriema; ponto 03- Pedra Pintada; ponto 04- pedra vermelha; ponto 05-formações rochosas no leito do rio; ponto 06-Apreciação de formações rochosas singulares; ponto 07-pedra do sol; ponto 08-vista do topo da serra no vale; ponto 09-Pedra do Cachorro; ponto 10-leito do riacho. Fonte: Desenvolvida pelos Autores.

\section{CONCLUSÕES}

Nas visitas à área correspondente ao vale do Riacho São José, pode-se verificar o potencial da geodiversidade e de grandes proporções. Por toda a extensão do vale são observadas feições geológicas e geomorfológicas de grande interesse e potencial, que podem ser classificadas como geossítios para estudo e visitação, configurando o vale como os valores e as características de um geoparque que deve ser reconhecido.

Este trabalho demostrou o potencial que a rede de drenagem do vale possui no que se refere à geodiversidade. Além de registrar algumas das belezas do lugar, podem ser desenvolvidas, no vale, propostas que tornem os geossítios mais conhecidos, tais como a criação de trilhas que aproveitem o potencial geoturístico, científico e estético do vale, aulas de campo e passeios didáticos, incentivo a práticas de rapel e escaladas. O geoturismo se mostra bastante atraente, desde que tenha como finalidade a divulgação da geodiversidade do vale e o desenvolvimento sustentável na região correspondente. A criação de trilhas, para promover o conhecimento, e esclarecimentos sobre a geografia e a geomorfologia da região (para que os visitantes adquiram conhecimentos sobre os fenômenos que configuraram a paisagem do vale), são boas formas de geoconservação, divulgação das geociências, podendo proporcionar um melhor aproveitamento dos recursos bióticos e abióticos do município de Caetés. 


\section{AGRADECIMENTOS}

A UPE - Universidade de Pernambuco, pelo fornecimento dos equipamentos necessários para o mapeamento. E ao grupo de pesquisas do Vale do Riacho São José.

\section{REFERÊNCIAS}

BACI, D de La C.[et al]. Geoparque: estratégia de geoconservação e projetos educacionais. Revista do Instituto de Geociências da USP. Publicação especial. São Paulo. V.5, p. 7-15, out, 2009.

BEZERRA, Rita de Cássia Lima Bezerra et al. Educação Ambiental. Fortaleza: Global Geoparks Network, 2011.

BRILHA, J.B.R. Patrimônio geológico e geoconservação: a conservação da natureza na sua vertente geológica. São Paulo: Palimage editora, 2005, 190p.

A importância dos geoparques no ensino e divulgação das Geociências. Revista do Instituto de Geociências da USP. Publicação especial. São Paulo. V.5, p. 7-15, out, 2009.

COMPANHIA DE PESQUISA EM RECURSOS MINERAIS-CPRM. Serviço Geológico do Brasil. Projeto Geoparques. 2005 Disponível em:

http://www.cprm.gov.br/publique/media/geologia_ambiental-06.pdf. Acesso em maio de 2014

CPRM - Serviço Geológico do Brasil Projeto cadastro de fontes de abastecimento por água subterrânea. Diagnóstico do município de Caetés, estado de Pernambuco / Organizado [por] João de Castro Mascarenhas, Breno Augusto Beltrão, Luiz Carlos de Souza Junior, Manoel Júlio da Trindade G. Galvão, Simeones Neri Pereira,

Jorge Luiz Fortunato de Miranda. Recife: CPRM/PRODEEM, 2005. Disponível <em:www.cprm.gov.br/rehi/ atlas/pernambuco/relatorios/CAET033.pdf> acesso em maio de 2014.

Gray, M. 2004. Geodiversity: valuing and conserving abiotic nature. John Wiley and Sons, Chichester, England.434 p.

RUCHKYS, U. A. 2007. Patrimônio Geológico e Geoconservação no Quadrilátero Ferrífero, Minas Gerais: potencial para a criação de um geoparque da UNESCO. Instituto de Geociências, Universidade Federal de Minas Gerais. Belo Horizonte. Tese de Doutorado, 211p. 